\title{
SOLVABILITY OF MULTI-POINT VALUE PROBLEMS WITH INTEGRAL CONDITION AT RESONANCE
}

\author{
RABAH KHALDI ${ }^{1, *}$ AND MOHAMMED KOUIDRI ${ }^{2}$ \\ ${ }^{1}$ Laboratory of Advanced Materials, Faculty of Sciences, Badji Mokhtar-Annaba University, P.O. Box 12, \\ 23000 Annaba, Algeria \\ ${ }^{2}$ Kasdi Merbah Ourgla University P.0.30000 Ourgla, Algeria \\ ${ }^{*}$ Corresponding author: rkhadi@yahoo.fr
}

\begin{abstract}
In this paper, we study a boundary value problem at resonance with a multi-integral boundary conditions. By constructing suitable operators, we establish an existence theorem upon the coincidence degree theory of Mawhin. An example is given to show the effectiveness of our results.
\end{abstract}

\section{INTRODUCTION}

Boundary value problem involves ordinary differential equation with non local condition appears in physical science and applied mathematics. Moreover the theory of boundary value problems with integral condition is found in deferent areas like applied mathematics and applied physics for example plasma physics, heat conduction, themo-elasticity, underground water flew. In recent years, the boundary value problem at resonance for ordinary differential equations have been extensively studied and many results have been obtained, we refer to [1], [2], [5]- [7], [10]- [12] and the references therein. Moreover, lots of works on multi-point boundary value problems have appeared, for examples, see [3]- [10].

Received 2017-12-17; accepted 2018-02-07; published 2018-05-02.

2010 Mathematics Subject Classification. 34B40, 34B15.

Key words and phrases. boundary value problem at resonance; existence of solution; coincidence degree; integral condition. (c)2018 Authors retain the copyrights of their papers, and all open access articles are distributed under the terms of the Creative Commons Attribution License. 
The goal of this paper is to provide sufficient conditions that ensure the existence of solutions for the following multi-point boundary value problem (BVP)

$$
\begin{gathered}
x^{\prime \prime}(t)=f\left(t, x(t), x^{\prime}(t)\right), t \in(0,1) \\
x(0)=0, x(1)=\sum_{k=1}^{m} \lambda_{k} \int_{0}^{\eta_{k}} x(t) d t,
\end{gathered}
$$

where $f:[0,1] \times \mathbb{R}^{2} \rightarrow \mathbb{R}$ is caratheodory function, $\eta_{k} \in(0,1)$ and $\sum_{k=1}^{m} \lambda_{k} \eta_{k}^{2}=2$.

We say that the (BVP) (1.1)-(1.2) is a resonance problem if the dimension of the kernel of the linear operator $L x=x^{\prime \prime}$ is not less than one under the boundary conditions 1.2. Otherwise, we call them a problem at nonresonance.

In the present work, if $\sum_{k=1}^{m} \lambda_{k} \eta_{k}^{2}=2$, then, (BVP) (1.1)-(1.2) is at resonance, since equation

$$
x^{\prime \prime}(t)=0, t \in(0,1)
$$

with boundary condition 1.2 has nontrivial solutions $x(t)=c t, c \in \mathbb{R}, t \in[0,1]$.

This paper is organized as follows, in section 2 we stated some definitions and lemmas needed in our proofs. In section 3 we treated the existence of solution by using the coincidence degree theory of Mawhin [9], [10]. we ended by giving an example illustrating the previous results.

\section{Preliminaries}

For the convenience of the reader to understand the coincidence degree theory, we briefly recall some notations, definitions and theorems which will be used later.

Definition 2.1. Let $X, Y$, be reaI Banach spaces, the linear operator $L: \operatorname{dom} L \subset X \rightarrow Y$ is said to be a Fredholm map of index zero provided that $\operatorname{ker} L$, the kernel of $L$, is of the same finite dimension as the $Y / \operatorname{Im} L$, where $\operatorname{Im} L$ is the image of $L$.

Let $L$ be a Fredholm map of index zero, and $P: X \rightarrow X, Q: Y \rightarrow Y$ be continuous projectors, such that $\operatorname{Im} P=\operatorname{ker} L, K \operatorname{er} Q=\operatorname{Im} L . \quad$ Then $X=\operatorname{ker} L \oplus \operatorname{ker} P, Y=\operatorname{Im} L \oplus \operatorname{Im} Q$, thus $\left.L\right|_{\operatorname{dom} L \cap \operatorname{ker} P}$ : $\operatorname{dom} L \cap \operatorname{ker} P \rightarrow \operatorname{Im} L$ is invertible, denote its inverse by $K_{P}$.

Definition 2.2. Let $L$ be a Fredholm map of index zero and $\Omega$ be an open bounded subset of $X$, such that $\operatorname{dom} L \cap \Omega \neq \phi$, the map $N: X \rightarrow Y$ is said to be $L-$ compact on $\bar{\Omega}$, if $Q N(\bar{\Omega})$ is bounded and $K_{p}(I-Q) N: \bar{\Omega} \rightarrow X$ is compact. 
Theorem 2.1. ([13]) Let $L$ be a Fredholm operator of index zero and let $N$ be $L$-compact on $\bar{\Omega}$. Assume that the following conditions are satisfied.

(i) $L x \neq \lambda N x$, for every $(x, \lambda) \in[(\operatorname{dom} L \backslash \operatorname{Ker} L) \cap \partial \Omega] \times(0,1)$.

(ii) $N x \notin \operatorname{Im} L$, for every $x \in \operatorname{Ker} L \cap \partial \Omega$.

(iii) $\operatorname{deg}\left(Q N_{\mid \operatorname{ker} L}, \operatorname{ker} L \cap \Omega, 0\right) \neq 0$, where $Q: Y \rightarrow Y$ is a projection as above with $\operatorname{Im} L=\operatorname{ker} Q$.

Then, the equation $L x=N x$ has at least one solution in $\operatorname{dom} L \cap \bar{\Omega}$.

In the following, we shall use the classical Banach spaces $X=C^{1}[0,1]$ and $Y=L^{1}[0,1]$ equipped respectively with the norm $\|x\|=\max \left\{\|x\|_{\infty},\left\|x^{\prime}\right\|_{\infty}\right\},\|x\|_{\infty}=\max _{t \in[0,1]}|x(t)|$ and $\|y\|_{1}=\int_{0}^{1}|y(t)| d t$.

We will use the space $A C^{2}[a, b]=\left\{u \in C^{1}[a, b], u^{\prime} \in A C[a, b]\right\}$, where $A C[a, b]$ is the space of absolutely continuous functions on $[a, b]$.

\section{Existence of Solutions}

Define the operator $L: \operatorname{dom} L \subset X \rightarrow Y$ by $L x=x^{\prime \prime}$, where

$$
\operatorname{dom} L=\left\{x \in W^{2,1}(0,1): x(0)=0, x(1)=\sum_{k=1}^{m} \lambda_{k} \int_{0}^{\eta_{k}} x(t) d t ; \eta_{k} \in(0,1), \sum_{k=1}^{m} \lambda_{k} \eta_{k}^{2}=2\right\} .
$$

Let $N: X \rightarrow Y$ the operator

$$
N x(t)=f\left(t, x(t), x^{\prime}(t)\right), t \in(0,1) .
$$

Then, the equation 1.1, can be written as $L x=N x$.

Next, in order to apply Theorem 2.1, we need the following Lemma.

Lemma 3.1. (i) $\operatorname{ker} L=\{x \in \operatorname{dom} L: x=c t, c \in \mathbb{R}, t \in[0,1]\}$;

(ii) $\operatorname{Im} L=\left\{y \in Y: \int_{0}^{1}(1-s) y(s) d s-\frac{1}{2} \sum_{k=1}^{k=m} \lambda_{k} \int_{0}^{\eta}\left(\eta_{k}-s\right)^{2} y(s) d s=0\right\}$;

(iii) $L: \operatorname{dom} L \subset X \rightarrow Y$ is a Fredholm operator of index zero, and the linear continuous projector operator $Q: Y \rightarrow Y$ can be defined as

$$
Q y(t)=k \cdot(R y) \cdot t
$$

where

$$
R y=\int_{0}^{1}(1-s) y(s) d s-\frac{1}{2} \sum_{k=1}^{m} \lambda_{k} \int_{0}^{\eta_{k}}\left(\eta_{k}-s\right)^{2} y(s) d s
$$

and

$$
k^{-1}=\frac{1}{6}-\frac{1}{24} \sum_{k=1}^{m} \lambda_{k} \eta_{k}^{4}
$$

(iv) The linear operator $K_{p}: \operatorname{Im} L \rightarrow \operatorname{dom} L \cap \operatorname{ker} P$ can be written as

$$
K_{p} y=\int_{0}^{t}(t-s) y(s) d s
$$


Moreover, for all $y \in \operatorname{Im} L$ we have

$$
\left\|K_{p} y\right\| \leq\|y\|_{1} .
$$

Proof. (i) For $x \in \operatorname{ker} L$, we have $x^{\prime \prime}(t)=0$. Then, we obtain $x(t)=a+b t$, where $a, b \in \mathbb{R}$.

From $x(0)=0$, we have $a=0$.

Again, since $\sum_{k=1}^{m} \lambda_{k} \eta_{k}^{2}=2$, then from $x(1)=\sum_{k=1}^{k=m} \lambda_{k} \int_{0}^{\eta_{k}} x(t) d t$, we get

$$
\operatorname{ker} L=\{x \in \operatorname{dom} L: x=c t, c \in \mathbb{R}, t \in[0,1]\}
$$

(ii) To prove that

$$
\operatorname{Im} L=\left\{y \in Y: \int_{0}^{1}(1-s) y(s) d s-\frac{1}{2} \sum_{k=1}^{k=m} \lambda_{k} \int_{0}^{\eta_{k}}\left(\eta_{k}-s\right)^{2} y(s) d s=0\right\},
$$

we show that, the linear equation

$$
x^{\prime \prime}=y,
$$

has a solution $x(t)$ satisfied, $x(0)=0, x(1)=\sum_{k=1}^{m} \lambda_{k} \int_{0}^{\eta_{k}} x(t) d t, \sum_{k=1}^{m} \lambda_{k} \eta_{k}^{2}=2$, if and only if

$$
\int_{0}^{1}(1-s) y(s) d s-\frac{1}{2} \sum_{k=1}^{m} \lambda_{k} \int_{0}^{\eta}\left(\eta_{k}-s\right)^{2} y(s) d s=0 .
$$

In fact, by integrating equation 3.2 and tacking and account that $x(0)=0$, we get

$$
x(t)=x^{\prime}(0) t+\int_{0}^{t}(t-s) y(s) d s
$$

again from $x(1)=\sum_{k=1}^{k=m} \lambda_{k} \int_{0}^{\eta_{k}} x(t) d t$, we obtain

$$
\begin{aligned}
x^{\prime}(0)+\int_{0}^{1}(1-s) y(s) d s & =\sum_{k=1}^{m} \lambda_{k} \int_{0}^{\eta_{k}}\left[x^{\prime}(0) t+\int_{0}^{t}(t-s) y(s) d s\right] d t \\
& =x^{\prime}(0)+\sum_{k=1}^{m} \lambda_{k}\left[\int_{0}^{\eta_{k}} \int_{0}^{t}(t-s) y(s) d s d t\right] \\
& =x^{\prime}(0)+\frac{1}{2} \sum_{k=1}^{m} \lambda_{k}\left[\int_{0}^{\eta_{k}}\left(\eta_{k}-s\right)^{2} y(s) d s\right]
\end{aligned}
$$

which implies

$$
\int_{0}^{1}(1-s) y(s) d s-\frac{1}{2} \sum_{k=1}^{m} \lambda_{k}\left[\int_{0}^{\eta_{k}}\left(\eta_{k}-s\right)^{2} y(s) d s\right]=0
$$

(iii) For $y \in Y$, we take the projector $Q$ as

$$
Q y=k\left(\int_{0}^{1}(1-s) y(s) d s-\frac{1}{2} \sum_{k=1}^{m} \lambda_{k}\left[\int_{0}^{\eta_{k}}\left(\eta_{k}-s\right)^{2} y(s) d s\right]\right) t,
$$


where

$$
k^{-1}=\int_{0}^{1}(1-s) s d s-\frac{1}{2} \sum_{k=1}^{m} \lambda_{k}\left[\int_{0}^{\eta_{k}}\left(\eta_{k}-s\right)^{2} s d s\right]=\frac{1}{6}-\frac{1}{24} \sum_{k=1}^{m} \lambda_{k} \eta_{k}^{4} .
$$

It follows from $\operatorname{ker} Q=\operatorname{Im} L$ that $Y=\operatorname{Im} L \oplus \operatorname{Im} Q$, thus, $c o \operatorname{dim} L=\operatorname{dim} \operatorname{ker} L=1$.

Hence, $L$ is a Fredholm operator of index zero.

(iv) Taking $P: X \rightarrow X$ as follows,

$$
P x=x^{\prime}(0) t
$$

then, the generalized inverse $K_{p}: \operatorname{Im} L \rightarrow d o m L \cap \operatorname{ker} P$ of $L$ can be written as

$$
K_{p} y=\int_{0}^{t}(t-s) y(s) d s
$$

In fact, for $y \in \operatorname{Im} L$, we have

$$
\left(L K_{p}\right) y(t)=y(t)
$$

and, for $x \in d o m L \cap \operatorname{ker} P$, we know

$$
\left(K_{p} L\right) x(t)=\int_{0}^{t}(t-s) x^{\prime \prime}(s) d s=x(t)
$$

This shows that $K_{p}=\left(L_{\mid \operatorname{dom} L \cap \operatorname{ker} P}\right)^{-1}$.

Finally from the definition of $K_{p}$, we get

$$
\left\|K_{p} y\right\|_{\infty} \leq \int_{0}^{1}(1-s)|y(s)| d s \leq \int_{0}^{1}|y(s)| d s=\|y\|_{1}
$$

Now, we give the result on the existence of a solution for the problem (1.1)-(1.2).

Theorem 3.1. Assume that the following conditions are satisfied:

$\left(H_{1}\right)$ There exists nonnegative functions $\alpha, \beta, \gamma \in L^{1}[0,1]$, such that, for all $(x, y) \in \mathbb{R}^{2}, t \in[0,1]$, satisfying the following inequalities:

$$
|f(t, x, y)| \leq \alpha(t)|x|+\beta(t)|y|+\gamma(t)
$$

$\left(H_{2}\right)$ There exists a constant $M>0$, such that, for $x \in \operatorname{dom} L$, if $\left|x^{\prime}(t)\right|>M$, for all $t \in[0,1]$, then,

$$
\int_{0}^{1}(1-s) f\left(s, x(s), x^{\prime}(s)\right) d s-\frac{1}{2} \sum_{k=1}^{m} \lambda_{k} \int_{0}^{\eta_{k}}\left(\eta_{k}-s\right)^{2} f\left(s, x(s), x^{\prime}(s)\right) d s \neq 0
$$

$\left(H_{3}\right)$ There exists a constant $M^{*}>0$, such that, for any $x(t)=c t \in \operatorname{ker} L$ with $|c|>M^{*}$ either 


$$
c\left[\int_{0}^{1}(1-s) f(s, x(s), c) d s-\frac{1}{2} \sum_{k=1}^{m} \lambda_{k} \int_{0}^{\eta_{k}}\left(\eta_{k}-s\right)^{2} f(s, x(s), c) d s\right]<0
$$

or

$$
c\left[\int_{0}^{1}(1-s) f(s, x(s), c) d s-\frac{1}{2} \sum_{k=1}^{k=m} \lambda_{k} \int_{0}^{\eta_{k}}\left(\eta_{k}-s\right)^{2} f(s, x(s), c) d s\right]>0
$$

then $B V P$ (1.1)-(1.2) has at least one solution in $C^{1}[0,1]$, provided $\|\alpha(t)\|+\|\beta(t)\| \leq \frac{1}{2}$.

Next, in order to prove Theorem 3.1, we need the following Lemma.

Lemma 3.2. Suppose that $\Omega$ is an open bounded subset of $X$ such that $\operatorname{dom} L \cap \bar{\Omega} \neq \emptyset$. Then $N$ is $L$-compact on $\bar{\Omega}$.

Proof. Suppose that $\Omega \subset X$ is a bounded set. Without loss of generality, we may assume that $\Omega=B(0, r)$, then for any $x \in \bar{\Omega},\|x\| \leq r$. For $x \in \bar{\Omega}$, and by condition 3.3, we obtain

$$
\begin{aligned}
|Q N x| & \leq k \int_{0}^{1}\left|f\left(s, x(s), x^{\prime}(s)\right)\right| d s+\frac{k}{2} \sum_{k=1}^{m} \lambda_{k} \int_{0}^{\eta_{k}}\left|f\left(s, x(s), x^{\prime}(s)\right)\right| d s \\
& \leq k \int_{0}^{1}|\alpha(s)||x(s)|+|\beta(s)|\left|x^{\prime}(s)\right|+|\gamma(t)| d s+\frac{k}{2} \sum_{k=1}^{m} \lambda_{k} \int_{0}^{\eta_{k}}|\alpha(s)||x(s)|+|\beta(s)|\left|x^{\prime}(s)\right|+|\gamma(t)| d s \\
& \leq\left(k+\frac{k}{2} \sum_{k=1}^{m} \lambda_{k}\right)\left[r\left(\|\alpha(t)\|_{1}+\|\beta(t)\|_{1}\right)+\|\gamma(t)\|_{1}\right]
\end{aligned}
$$

thus,

$$
\|Q N x\|_{1} \leq\left(k+\frac{k}{2} \sum_{k=1}^{m} \lambda_{k}\right)\left[r\left(\|\alpha(t)\|_{1}+\|\beta(t)\|_{1}\right)+\|\gamma(t)\|_{1}\right],
$$

which implies that $Q N(\bar{\Omega})$ is bounded. Next, we show that $K_{P}(I-Q) N(\bar{\Omega})$ is compact. For $x \in \bar{\Omega}$, by condition 3.3 we have

$$
\|N x\|_{1}=\int_{0}^{1}\left|f\left(t, x(s), x^{\prime}(s)\right)\right| d s \leq r\left(\|\alpha(t)\|_{1}+\|\beta(t)\|_{1}\right)+\|\gamma(t)\|_{1} .
$$

On the other hand, from the definition of $K_{P}$ and together with (3.1), (3.4) and (3.5) one gets

$$
\begin{aligned}
\left\|K_{P}(I-Q) N x\right\| & \leq\|(I-Q) N x\|_{1} \leq\|N x\|_{1}+\|Q N x\|_{1} \\
& \leq\left(1+k+\frac{k}{2} \sum_{k=1}^{m} \lambda_{k}\right)\left(r\left(\|\alpha(t)\|_{1}+\|\beta(t)\|_{1}\right)+\|\gamma(t)\|_{1}\right) .
\end{aligned}
$$

It follows that $K_{P}(I-Q) N(\bar{\Omega})$ is uniformly bounded.

Let us prove that $K_{P}(I-Q) N(\bar{\Omega})$ is equicontinuous. For any $x \in \bar{\Omega}$, and any $t_{1}, t_{2} \in[0,1], t_{1}<t_{2}$, we have

$$
\begin{gathered}
\left(K_{P}(I-Q) N x\right)\left(t_{1}\right)-\left(K_{P}(I-Q) N x\right)\left(t_{2}\right)= \\
=\mid \int_{0}^{t_{1}}\left(t_{1}-s\right)(I-Q) N x(s) d s
\end{gathered}
$$




$$
\begin{aligned}
& -\int_{0}^{t_{2}}\left(t_{2}-s\right)(I-Q) N x(s) d s \mid \\
\leq & {\left[\int_{0}^{t_{1}}\left(t_{2}-t_{1}\right)|(I-Q) N x(s)| d s\right.} \\
& \left.+\int_{t_{1}}^{t_{2}}\left(t_{2}-s\right)|(I-Q) N x(s)| d s\right] \rightarrow 0,
\end{aligned}
$$

as $t_{1} \rightarrow t_{2}$. On the other hand we have

$$
\begin{gathered}
\left|\left(K_{P}(I-Q) N x\right)^{\prime}\left(t_{1}\right)-\left(K_{P}(I-Q) N x\right)^{\prime}\left(t_{2}\right)\right| \\
=\left|\int_{0}^{t_{1}}(I-Q) N x(s) d s-\int_{0}^{t_{2}}(I-Q) N x(s) d s\right| \rightarrow 0,
\end{gathered}
$$

as $t_{1} \rightarrow t_{2}$. So $K_{P}(I-Q) N(\bar{\Omega})$ is equicontinuous. so, the Ascoli-Arzela theorem ensure that $K_{p}(I-Q) N$ : $\bar{\Omega} \rightarrow X$ is compact. The proof is complete

Now we give the proof of Theorem 3.1

Proof. Firstly, we need to construct the set $\Omega$ satisfying all the conditions in Theorem 2.1, which is separated into the following three steps.

Step 1. First we show that the following set

$$
\Omega_{1}=\{x \in \operatorname{dom} L \backslash \operatorname{ker} L: L x=\lambda N x, \text { forsome } \lambda \in[0,1]\}
$$

is bounded.

In fact, let $x \in \Omega_{1}$, we have $L x=\lambda N x$ and $L x \neq 0$, so $\lambda \neq 0$, thus $Q N x=0$, from which it yields

$$
\int_{0}^{1}(1-s) f\left(s, x(s), x^{\prime}(s)\right) d s-\frac{1}{2} \sum_{k=1}^{k=m} \lambda_{k} \int_{0}^{\eta_{k}}\left(\eta_{k}-s\right)^{2} f\left(s, x(s), x^{\prime}(s)\right) d s=0
$$

thus, from condition $\left(H_{2}\right)$ of Theorem 3.1, there exists $t_{0} \in[0,1]$, such that $\left|x^{\prime}\left(t_{0}\right)\right| \leq M$.

In view of

$$
x^{\prime}(0)=x^{\prime}\left(t_{0}\right)-\int_{0}^{t_{0}} x^{\prime \prime}(t) d t
$$

then,

$$
\|P x\|=\left|x^{\prime}(0)\right| \leq M+\left\|x^{\prime \prime}\right\|_{1} \leq M+\|N x\|_{1}
$$

Again for $x \in \Omega_{1}, x \in \operatorname{dom} L \backslash \operatorname{ker} L$, then $(I-P) x \in \operatorname{dom} L \cap \operatorname{ker} P$ and $L P x=0$, thus from Lemma 3.1 , we know

$$
\|(I-P) x\|=\|K p L(I-P) x\| \leq\|L(I-P) x\|_{1}=\|L x\|_{1} \leq\|N x\|_{1}
$$


From (3.6) and (3.7), we have

$$
\|x\| \leq\|P x\|+\|(I-P) x\| \leq M+2\|N x\|_{1}
$$

If condition 3.3 holds, then from (3.8), we obtain

$$
\|x\| \leq 2\left[\|\alpha\|_{1}\|x\|_{\infty}+\|\beta\|_{1}\left\|x^{\prime}\right\|_{\infty}+\|\gamma\|_{1}+\frac{M}{2}\right] .
$$

Since $\|x\|_{\infty} \leq\|x\|$, then from (3.9) it yields

$$
\|x\|_{\infty} \leq \frac{2}{1-2\|\alpha\|_{1}}\left[\|\beta\|_{1}\left\|x^{\prime}\right\|_{\infty}+\|\gamma\|_{1}+\frac{M}{2}\right]
$$

By using $\left\|x^{\prime}\right\|_{\infty} \leq\|x\|,(3.9)$ and (3.10) one has

$$
\left\|x^{\prime}\right\|_{\infty}\left[1-\frac{2\|\beta\|_{1}}{1-2\|\alpha\|_{1}}\right] \leq \frac{2}{1-2\|\alpha\|_{1}}\left[\|\gamma\|_{1}+\frac{M}{2}\right]
$$

therefore,

$$
\left\|x^{\prime}\right\|_{\infty}\left[\frac{1-2\|\alpha\|_{1}-2\|\beta\|_{1}}{1-2\|\alpha\|_{1}}\right] \leq \frac{1}{1-2\|\alpha\|_{1}}\left[2\|\gamma\|_{1}+M\right]
$$

i.e.

$$
\left\|x^{\prime}\right\|_{\infty} \leq \frac{2\left[\|\gamma\|_{1}+\frac{M}{2}\right]}{1-2\|\alpha\|_{1}-2\|\beta\|_{1}}
$$

thus, from (3.10) and (3.11), there exist $M_{1}>0$, such that

$$
\|x\| \leq M_{1}
$$

which proves that $\Omega_{1}$ is bounded.

Step 2. We will show that the set

$$
\Omega_{2}=\{x \in \operatorname{ker} L: N x \in \operatorname{Im} L\}
$$

is bounded.

Let $x \in \Omega_{2}$, then $x(t)=b t, b \in \mathbb{R}, t \in[0,1]$, and $Q N x=0$, therefor

$$
\int_{0}^{1}(1-s) f(s, b s, b) d s-\frac{1}{2} \sum_{k=1}^{k=m} \lambda_{k} \int_{0}^{\eta_{k}}\left(\eta_{k}-s\right)^{2} f(s, b s, b) d s=0
$$

In view of condition $\left(H_{2}\right)$ of Theorem 3.1, there exists $t_{0} \in[0,1]$, such that $\left|x^{\prime}\left(t_{0}\right)\right| \leq M$ that is $|b| \leq M$, so

$$
\left\|x^{\prime}\right\|_{\infty}=|b| \leq M
$$

from which, we get

$$
\|x\|=\max \left\{\|x\|_{\infty},\left\|x^{\prime}\right\|_{\infty}\right\}=|b| \leq M
$$


which implies that $\Omega_{2}$ is bounded.

Step 3. In the next, we show the boundedness of the following set

$$
\Omega_{3}=\{x \in \operatorname{ker} L:-\lambda J x+(1-\lambda) Q N x=0, \lambda \in[0,1]\},
$$

where, $J: \operatorname{ker} L \rightarrow \operatorname{Im} Q$ is the linear isomorphism given by $J(c t)=c t, \forall c \in \mathbb{R}, t \in[0,1]$.

If the first part of condition $\left(H_{3}\right)$ of Theorem 3.1 holds, that is, there exists $M^{*}>0$, such that, for any $c \in \mathbb{R}$, if $|c|>M^{*}$, then

$$
c\left[\int_{0}^{1}(1-s) f(s, x(s), c) d s-\frac{1}{2} \sum_{k=1}^{m} \lambda_{k} \int_{0}^{\eta_{k}}\left(\eta_{k}-s\right)^{2} f(s, x(s), c) d s\right]<0
$$

Let $x \in \Omega_{3}$, then $x(t)=c t$ and $\lambda J x=(1-\lambda) Q N x$, that is equivalently written as

$$
\lambda c=(1-\lambda) k\left[\int_{0}^{1}(1-s) f(s, x(s), c) d s-\frac{1}{2} \sum_{k=1}^{m} \lambda_{k} \int_{0}^{\eta_{k}}\left(\eta_{k}-s\right)^{2} f(s, x(s), c) d s\right],
$$

if $\lambda=1$, then $c=0$. Otherwise, if $|c|>M^{*}$, then in view of (3.12) and together with the fact that $k>0$, we get

$$
\lambda c^{2}=(1-\lambda) k c\left[\int_{0}^{1}(1-s) f(s, x(s), c) d s-\frac{1}{2} \sum_{k=1}^{m} \lambda_{k} \int_{0}^{\eta_{k}}\left(\eta_{k}-s\right)^{2} f(s, x(s), c) d s\right]<0
$$

which contradicts $\lambda c^{2} \geq 0$. Thus, $\Omega_{3} \subset\left\{x \in \operatorname{Ker} L:\|x\| \leq M^{*}\right\}$ is bounded.

On the other hand, If the second part of condition $\left(H_{3}\right)$ of Theorem 3.1 holds, by applying similar reasoning as above, we can prove that $\Omega_{3}$ is bounded.

Finally, we shall prove that all conditions of Theorem 2.1 are satisfied.

Let $\Omega$ be a bounded open subset of $X$, such that $\cup_{i=1}^{3} \bar{\Omega}_{i} \subset \Omega$. It follows from Lemma 3.1 that $L$ is a Fredholm operator of index zero. By Lemma 3.2, we have $N$ is $L$-compact on $\bar{\Omega}$. By virtue of the definition of $\Omega$, the assumptions (i) and (ii) are satisfied.

Now we prove that condition (iii) of Theorem 2.1 is satisfied. Let $H(x, \lambda)= \pm \lambda J x+(1-\lambda) Q N x$. Since $\bar{\Omega}_{3} \subset \Omega$, then $H(x, \lambda) \neq 0$ for every $x \in \operatorname{ker} L \cap \partial \Omega$. By the homotopy property of degree, we get

$$
\begin{aligned}
\operatorname{deg}\left(\left.Q N\right|_{\operatorname{ker} L}, \Omega \cap \operatorname{ker} L, 0\right) & =\operatorname{deg}(H(\cdot, 0), \Omega \cap \operatorname{ker} L, 0) \\
& =\operatorname{deg}(H(\cdot, 1), \Omega \cap \operatorname{ker} L, 0) \\
& =\operatorname{deg}( \pm J, \Omega \cap \operatorname{ker} L, 0) \neq 0 .
\end{aligned}
$$

Hence, the assumption (iii) of Theorem 2.1 holds.

Since all hypothesis of Theorem 2.1 are satisfied. Therefore, equation $L x=N x$ has at least one solution in $\operatorname{dom} L \cap \bar{\Omega}$; i.e. boundary value problem (1.1)-(1.2) has at least one solution in $X$. The proof is completed. 


\section{An Illustrative Example}

In this section we give an example to illustrate the usefulness of our main results.

Consider the multi-point boundary value problem

$$
(P)\left\{\begin{array}{c}
x^{\prime \prime}(t)=f\left(t, x(t), x^{\prime}(t)\right), t \in(0,1), \\
x(0)=0, x(1)=4 \int_{0}^{\frac{1}{2}} x(t) d t+\frac{16}{9} \int_{0}^{\frac{2}{3}} x(t) d t
\end{array}\right.
$$

with

$$
f(t, x, y)=\frac{t}{4} x+\left(\frac{1-t^{2}}{4}\right) y+t
$$

Since $\sum_{k=1}^{2} \lambda_{k} \eta_{k}^{2}=4\left(\frac{1}{2}\right)^{2}+\frac{16}{9}\left(\frac{3}{4}\right)^{2}=2$, the problem $(P)$ is at resonance.

We have

$$
|f(t, x, y)| \leq \alpha(t)|x|+\beta(t)|y|+\gamma(t)
$$

where $\alpha(t)=\frac{t}{4}, \beta(t)=\frac{1-t^{2}}{4}$ and $\gamma(t)=t$, then $\alpha, \beta$ are nonnegative and belong to $L^{1}[0,1]$, so, hypothesis $\left(H_{1}\right)$ of Theorem 3.1 is satisfied.

We claim that condition $\left(H_{2}\right)$ of Theorem 3.1 is satisfied, indeed, for $M=1.8214>0$ and $x \in \operatorname{domL}$, $x(t)=c t$, if $\left|x^{\prime}(t)\right|>M$, for all $t \in[0,1]$, then,

$$
\begin{aligned}
& \int_{0}^{1}(1-s) f\left(s, x(s), x^{\prime}(s)\right) d s-\frac{1}{2} \sum_{k=1}^{2} \lambda_{k} \int_{0}^{\eta_{k}}\left(\eta_{k}-s\right)^{2} f\left(s, x(s), x^{\prime}(s)\right) d s \\
= & \int_{0}^{1}(1-s)\left(\frac{c}{4}+s\right) d s-\frac{1}{2}\left(4 \int_{0}^{\frac{1}{2}}\left(\frac{1}{2}-s\right)^{2}\left(\frac{c}{4}+s\right) d s+\frac{16}{9} \int_{0}^{\frac{3}{4}}\left(\frac{3}{4}-s\right)^{2}\left(\frac{c}{4}+s\right) d s\right) \\
= & \frac{7}{96} c+\frac{17}{128} \neq 0 .
\end{aligned}
$$

Now, for $M^{*}=2>0$ and any $x(t)=c t \in \operatorname{ker} L$ with $|c|>M^{*}$, we have

$$
\begin{aligned}
& c\left[\int_{0}^{1}(1-s) f\left(s, x(s), x^{\prime}(s)\right) d s-\frac{1}{2} \sum_{k=1}^{2} \lambda_{k} \int_{0}^{\eta_{k}}\left(\eta_{k}-s\right)^{2} f\left(s, x(s), x^{\prime}(s)\right) d s\right] \\
= & \frac{7}{96} c^{2}+\frac{17}{128} c>0,
\end{aligned}
$$

consequently, condition $\left(H_{3}\right)$ of Theorem 3.1 is satisfied.

Finally, a simple calculus gives $\|\alpha\|_{1}+\|\beta\|_{1}=\frac{1}{8}+\frac{1}{6} \leq \frac{1}{2}$. We conclude from Theorem 3.1 that the problem $(P)$ has at least one solution in $C^{1}[0,1]$.

\section{REFERENCES}

[1] A. Guezane-Lakoud and A. Frioui, Third Order Boundary Value Problem with Integral Condition at Resonance, Math. Comput. Sci. 3 (1) (2013) 56-64. 
[2] A. Guezane Lakoud, R. Khaldi and A. Kılıçman, Solvability of a boundary value problem at resonance, Springer Plus 5 (2016), Art. ID 1504.

[3] A. Guezane-Lakoud, N. Hamidane and R. Khaldi, On a third-order three-point boundary value problem. Int. J. Math. Math. Sci. 2012 (2012), Art. ID 513189.

[4] A. Guezane-Lakoud, R. Khaldi, Study of a third-order three-point boundary value problem, AIP Conf. Proc., 1309(2010), 329-335.

[5] C. P. Gupta, Solvability of multi-point boundary value problems at resonance, Results Math. 28(1995), $270-276$.

[6] C. P. Gupta, A second order m-point boundary value problem at resonance, Nonlinear Anal. 24 (1995), $1483-1489$.

[7] C. P. Gupta, Existence theorems for a second order m-point boundary value problem at resonance, Internat. J. Math. Math. Sci. 18 (1995), no. 4, 705-710.

[8] N. Kosmatov, A multi-point boundary value problem with two critical conditions. Nonlinear Anal. 65 (2006), no. 3, $622-633$.

[9] S. K. Ntouyas and P. Ch. Tsamatos, Multi-point boundary value problems for ordinary differential equations. An. Ştiinţ. Univ. Al. I. Cuza Iaşi. Mat. (N.S.) 45 (1999), no. 1, 57-64 (2000).

[10] Lin, X., Z. Du. and F. Meng, A note on a third-order multi-point boundary value problem at resonance. Math. Nachr. 284 (2011), $1690-1700$.

[11] R. Ma, Multiplicity results for a third order value problem at resonance, Nonlinear Anal. 32 (1998), no. 4, $493-499$.

[12] R. K. Nagle and K. L. Pothoven, On a third-order nonlinear boundary value problems at resonance, J. Math. Anal. Appl. 195 (1995), no 1, 148-159.

[13] J. Mawhin, Topological degree methods in nonlinear boundary value problems. Expository lectures from the CBMS Regional Conference held at Harvey Mudd College, Claremont, Calif., June 9-15, 1977. CBMS Regional Conference Series in Mathematics, 40. American Mathematical Society, Providence, R.I., 1979.

[14] Mawhin, J. Topological degree and boundary value problems for nonlinear differential equations. Topological methods for ordinary differential equations (Montecatini Terme, 1991), 74-142, Lecture Notes in Math., 1537, Springer, Berlin, 1993. 